\title{
Association of thymidylate synthase gene 3'-untranslated region polymorphism with sensitivity of non-small cell lung cancer to pemetrexed treatment: TS gene polymorphism and pemetrexed sensitivity in NSCLC
}

\author{
Xia Wang ${ }^{1+}$, Yadi Wang ${ }^{2+}$, Yue Wang ${ }^{1}$, Jian Cheng ${ }^{1}$, Yanyun Wang ${ }^{1}$ and Minwen $\mathrm{Ha}^{1 *}$
}

\begin{abstract}
Background: Thymidylate synthase (TS) is a key enzyme responsible for DNA synthesis and repair. Altered expression of TS protein or TS gene polymorphisms has been associated with cancer progression and treatment response. This study investigated the expressions of TS and its gene SNPs in non-small cell lung cancer (NSCLC), and then its association with sensitivity to pemetrexed treatment. Immunohistochemistry and QRT-PCR were performed on 160 resected NSCLC specimens and corresponding normal tissues to assess the expressions of TS protein and TS mRNA, and for associations with clinicopathological data. Blood samples of 106 lung adenocarcinoma patients were examined for polymorphisms of the TS gene 3'-UTR 1494del $6 \mathrm{bp}$, which was then investigated for associations with responses of the patients to pemetrexed treatment and survival.

Results: Expression of both TS protein and its mRNA was elevated in NSCLC tissues compared with matched normal tissues, and significantly higher in lung squamous cell carcinoma than in lung adenocarcinoma. TS expression was associated with poor tumor differentiation. Furthermore, the genotyping data showed that 56\% of lung adenocarcinoma patients had the TS gene 3'-UTR $1494 \mathrm{bp}(-6 \mathrm{bp} /-6 \mathrm{bp})$ genotype and the rest had TS gene 3'-UTR $1494 \mathrm{bp}(-6 \mathrm{bp} /+6 \mathrm{bp})$. There was no TS 3'-UTR $1494 \mathrm{bp}(+6 \mathrm{bp} /+6 \mathrm{bp})$ genotype in any patients. Statistical analysis revealed that gender, tumor stage, and TS 3'-UTR 1494del 6 bp polymorphism were significant prognostic factors after short-term pemetrexed treatment. Log-rank analysis revealed that patients with the ( $-6 \mathrm{bp} /-6 \mathrm{bp})$ genotype had significantly better progression-free and overall survival than patients with ( $-6 \mathrm{bp} /+6 \mathrm{bp})$.

Conclusions: This study showed that TS protein is highly expressed in NSCLC and that polymorphisms of TS 3'-UTR 1494del 6 bp are associated with sensitivity of lung adenocarcinoma patients to pemetrexed treatment. This suggests that TS gene polymorphisms should be further evaluated as prognostic markers for personalized therapy in lung adenocarcinoma.
\end{abstract}

Keywords: Lung adenocarcinoma, Non-small cell lung cancer, Pemetrexed treatment, Thymidylate synthase, TS gene polymorphism

\footnotetext{
* Correspondence: hamw2002@yahoo.com.cn

${ }^{\dagger}$ Equal contributors

'Department of Oncology, First Affiliated Hospital of Liaoning Medical

College, Jinzhou, China

Full list of author information is available at the end of the article
} 


\section{Background}

Lung cancer was the leading cause of cancer death in men and the second leading cause in women worldwide in 2008. Although lung cancer incidence is slowly decreasing in developed countries, the number of lung cancer cases is still increasing in China and other developing countries [1]. Over $75 \%$ of all lung cancer cases are NSCLC, which include adenocarcinoma, squamous cell carcinoma, and large-cell carcinoma [2]. Common treatments for NSCLC include surgery, chemotherapy, radiation therapy, and palliative care depending on the cancer type, stage, and other factors. Primary chemotherapy is also given for advanced and metastatic NSCLC. A combination of platinum chemotherapy compounds (cisplatin or carboplatin) with gemcitabine, vinorelbine, or taxanes (paclitaxel or docetaxel) is a widely used regimen for first-line treatment of stage IIIB or IV NSCLC [2]. However, there is no standard regimen for local recurrence of NSCLC. In 2006, the National Comprehensive Cancer Network recommended pemetrexed as a single agent for second-line treatment of advanced NSCLC [3].

Pemetrexed is an antifolate drug that inhibits growth of a variety of tumor types by targeting the folate-dependent enzymes dihydrofolate reductase, glycinamide ribonucleotide formyltransferase, and thymidylate synthase (TS); but is most potent on TS $[4,5]$. To date, three large phase III clinical trials have provided strong evidence for use of pemetrexed in control of NSCLC [5-8]. The data also showed that tumor histology was able to predict the sensitivity of pemetrexed therapy in lung cancer, and that expression of TS mRNA and TS protein differed between squamous cell lung cancer or NSCLC and lung adenocarcinoma [5]. However, patients with similar histotype and disease stage might respond very differently to identical treatments, which suggests that TS genotypes contribute to these patients' sensitivity to chemotherapeutic drugs. Therefore, clinical studies have begun to focus on developing personalized treatments based on both histotype and genotype to improve the efficacy of chemotherapy.

Indeed, it has been reported that the expression of TS was induced in various cancers, including gastric, colorectal, breast, and bladder cancers, compared with corresponding normal tissues [6,7]. Functionally, TS generates thymidine monophosphate (dTMP), which is subsequently phosphorylated to thymidine triphosphate for use in DNA synthesis and repair. TS is localized on chromosome 18, covering $16 \mathrm{~kb}$, and with 7 exons that translates into a $72-\mathrm{kD}$ protein and functions as a homodimer. A previous study showed that a 6-bp variation at $1494 \mathrm{bp}$ of the TS 3'-UTR was associated with TS mRNA stability and reduced TS protein expression [8]. Other studies showed that this polymorphism also affected sensitivity to anticancer drugs and prognoses of breast and gastrointestinal cancers $[6,9-11]$.
In the present study, we first detected expression of TS mRNA and TS protein in NSCLC tissue specimens, and then determined the genotype at the TS 3'-UTR at 1494del in 106 lung adenocarcinoma patients to investigate its association with sensitivity to pemetrexed.

\section{Methods}

\section{Tissue specimens}

A total of 160 chemotherapy-naive patients received surgery at the Department of Thoracic Surgery, First Affiliated Hospital of Liaoning Medical College between January 2006 and March 2010. All tumors were confirmed histologically as adenocarcinoma or squamous cell carcinoma of the lung. Representative fragments of fresh tumor and adjacent normal-appearing lung tissue were obtained and immediately snap frozen and stored in liquid nitrogen until used. The remaining tissue was fixed in formalin and embedded in paraffin. Our hospital review board, the Ethics Committee of First Affiliated Hospital of Liaoning Medical College, approved our study, and each patient or their legal guardian signed a consent form for participation in the study.

\section{Semi-quantitative reverse-transcription (RT) PCR}

Total RNA was extracted from tissue specimens using Trizol (Tiangen Biotech, Beijing) in accordance with the manufacturer's instructions. cDNA was transcribed from RNA samples using an iScript cDNA synthesis kit (BioRad, Hercules, CA). Primers for amplification of TS mRNA (NC_000018) were: 5'-TTGGACAGCCTGGGA TTCTC-3' (forward) and 5'-AGCTGGCGATGTTGAAA GG-3' (reverse). Primers for $\beta$-actin were 5'-GCATCC ACGAAACTACCTT-3' (forward) and 5'-CTCGTCATA CTCCTGCTT-3' (reverse), which were synthesized by Aoke Biotech (Beijing). The PCR amplification was set to $94^{\circ} \mathrm{C}$ for $2 \mathrm{~min}$, then 35 cycles of $94^{\circ} \mathrm{C}$ for $45 \mathrm{~s}, 58^{\circ} \mathrm{C}$ for $45 \mathrm{~s}$, and $65^{\circ} \mathrm{C}$ for $90 \mathrm{~s}$, and then $65^{\circ} \mathrm{C}$ for $10 \mathrm{~min}$. PCR products were separated in a $1.5 \%$ agarose gel by electrophoresis at $90 \mathrm{~V}$ for one hour. $\beta$-actin mRNA was the internal control.

For semi-quantitative PCR, we first tested different cycles of PCR to amplify the TS mRNA (25-40 cycles) and chose 35 cycles for our study. After PCR products were resolved in a $1.5 \%$ gel, UV-light photos were taken and the density of the bands was quantified using Gel-pro Analyzer 4.5 software (Media Cybernetics, USA). The expression of TS mRNA was normalized as $47 \%$ of $\beta$-actin.

\section{Immunohistochemistry}

Tissue sections were prepared, deparaffinized, and rehydrated in accordance with standard protocols. Endogenous peroxidase activity was quenched with $6 \%$ hydrogen peroxide in methanol for $30 \mathrm{~min}$. Antigen retrieval was achieved by heating the tissue sections in a pressure 
cooker using $10 \mathrm{mM}$ citrate buffer at $\mathrm{pH}$ 6. To block nonspecific binding, the sections were incubated with normal goat serum diluted in phosphate buffered saline (PBS) for $30 \mathrm{~min}$. After washing with PBS, the sections were incubated with primary antibody overnight at $4^{\circ} \mathrm{C}$ followed by a 30-min incubation with horseradish peroxidaseconjugated secondary antibody at room temperature. The monoclonal mouse anti-human antibody against thymidylate synthase and a PV-6000 immunohistochemistry kit were purchased from Zhongshan (Beijing, China). The sections were then incubated in a 3,3'-diaminobenzidine chromogen solution and counterstained with Mayer's hematoxylin. Negative controls were prepared as above, but without the primary antibody. Sections with known TS expression served as the positive controls. The intensity of TS expression was scored as $0,1+, 2+$, and $3+$. A score $\geq 2+$ was classified as positive for TS.

\section{Patients and treatment plan}

One hundred and six patients were recruited from the Department of Oncology, First Affiliated Hospital of Liaoning Medical College between January 2006 and March 2010. Of the 160 consecutive chemotherapy-naive patients who received surgery at the Department of Thoracic Surgery, 119 cases were lung adenocarcinoma and 41 were lung squamous cell carcinoma. Thirteen patients from the 119 lung adenocarcinomas were lost to followup, resulting in 106 cases for data analysis.
The patients were histologically or cytologically confirmed as stage IIIB or IV lung adenocarcinoma and subjected to pemetrexed treatment. The patients had adequate organ functions and an Eastern Cooperative Oncology Group (ECOG) performance status of 0, 1, or 2. The hospital's ethics review board approved the study protocol for pemetrexed therapy and all patients signed written informed consent before treatment.

Prior to pemetrexed infusion, the patients took $4 \mathrm{mg}$ dexamethasone orally twice a day for three days. The patients also took $400 \mu \mathrm{g}$ folic acid once a day, beginning 7 days before pemetrexed infusion and for 21 days after the final treatment. In addition, the patients were injected (intravenous) with $1000 \mu \mathrm{g}$ vitamin $\mathrm{B}_{12}$ on the day before the first pemetrexed treatment and then once every three cycles of pemetrexed administration thereafter. The patients were given $500 \mu \mathrm{g} / \mathrm{m}^{2}$ pemetrexed through a single intravenous infusion that lasted more than $10 \mathrm{~min}$, repeated once every 3 weeks.

Before entering the study, these patients underwent a physical examination and tumor measurement with computed tomography (CT) or magnetic resonance imaging (MRI). Overall survival (OS) after pemetrexed use was measured from the first date of pemetrexed therapy to the date of death or the last follow-up. A perspective clinical follow-up, including chest CT scan and telephone inquiry, was performed for all patients. Followup time was calculated from the end of chemotherapy
A

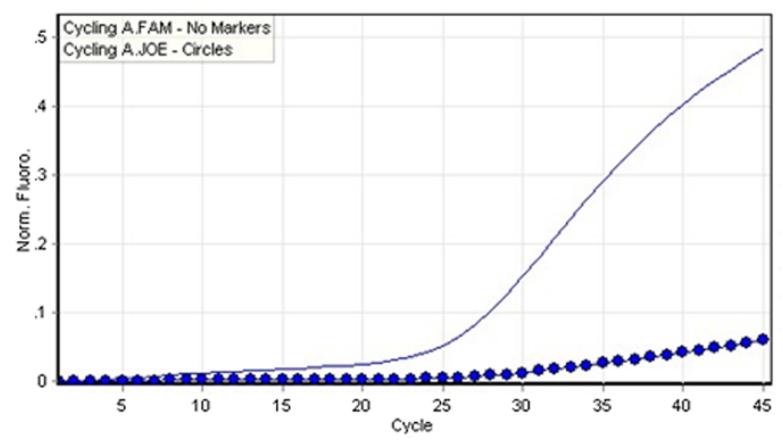

B

$-6 b p /-6 b p$

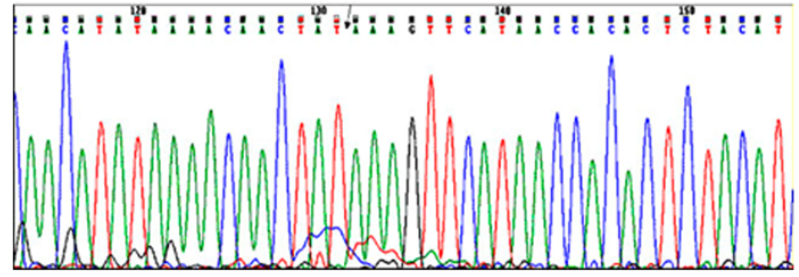

C

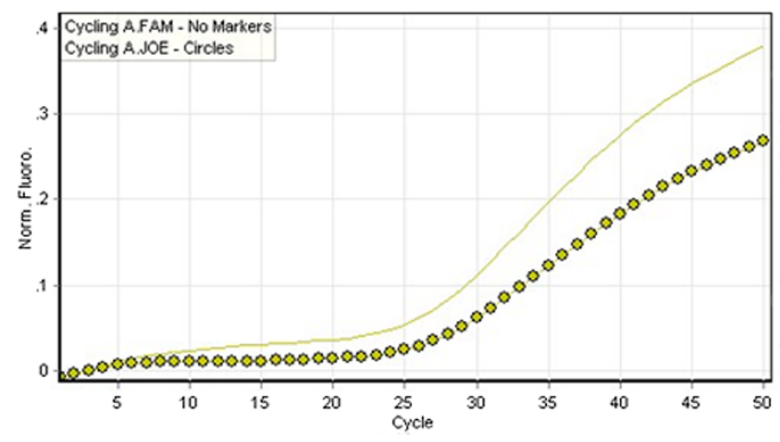

D

$-6 \mathrm{bp} /+6 \mathrm{bp}$

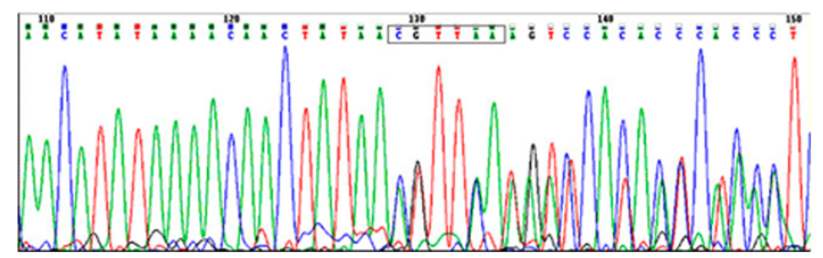

Figure 1 Detection of TS gene 3'-UTR 6 bp polymorphism at $1494 \mathrm{bp}$. Genomic DNA was extracted from blood from patients and subjected to qPCR analysis of the TS gene polymorphism and then to DNA sequencing analysis. A and C, QPCR amplification curves show TS $3^{\prime}-$ UTR 1494 bp (-6 bp/-6 bp) and (-6 bp/+6 bp) polymorphisms. B and D, DNA sequencing data on TS 3'-UTR 1494 bp (-6 bp/-6 bp) and ( $-6 \mathrm{bp} /+6 \mathrm{bp})$. 
until death, recurrence, metastasis, or the completion of the study in June 2011. Disease status was assessed according to the Response Evaluation Criteria in Solid Tumors [12]. Complete response (CR) or partial response (PR) was considered evidence of short-term effective treatment. A treatment that resulted in stable disease (SD) or progressive disease (PD) was judged ineffective. Long-term efficacy analysis included evaluations of OS and progression-free survival (PFS). PFS was defined as the time from the first date of pemetrexed therapy to the date of documented progression or death from any cause.

\section{Quantitative PCR (qPCR) detection of the TS gene 3'-UTR polymorphism}

Genomic DNA was extracted from peripheral blood of the patients using the AxyPrep Mag Blood Genomic DNA kit (Axygen, Union City, CA) in accordance with the manufacturer's instructions. To detect the TS gene 3'-UTR polymorphism at $1494 \mathrm{bp}$, the fragment containing the region was amplified using qPCR with primers rs34489327-FP (5'-GAGCTGAGTAACACCATC GA-3'), rs34489327-RP (5'-AGGAAGGAACTGAGC-A GATAA-3'), rs34489327-PJ (5'-FAM-TTATGAACTTT TTAAAGA-MGB-3'), and rs34489327-CR (5'-HEX-AT GAACTTTATAGTTGTT-MGB-3') (AllGlo ${ }^{\mathrm{TM}}$ ). The PCR program was set at $95^{\circ} \mathrm{C}$ for $5 \mathrm{~min}$, and then 45 cycles of $95^{\circ} \mathrm{C} 10 \mathrm{~s}$ and $55^{\circ} \mathrm{C} 40 \mathrm{~s}$ using a Rotor-Gene $3000 \mathrm{~A}$ (Corbett Research, Australia). Representative qPCR reaction curves of the TS 3'-UTR 1494 genotypes $(-6 \mathrm{bp} /-6 \mathrm{bp})$ and $(-6 \mathrm{bp} /+6 \mathrm{bp})$ are shown in Figure $1 \mathrm{~A}$ and $\mathrm{C}$. Three randomly selected PCR products from each genotype were subjected to DNA sequence analysis for confirmation of the TS 3'-UTR alterations.

\section{Statistical analyses}

All statistical analyses were performed using SPSS 17.0 software (SPSS, Chicago, IL). For the assessing the association of TS expression with clinicopathological features, the probability $(P)$ value was calculated using the chi-squared $\left(\mathrm{X}^{2}\right)$ test. TS mRNA expression is shown as mean \pm standard deviation.

Grade correspondence analysis was performed using the non-parametric Spearman's rank correlation coefficient. Expressions of TS mRNA and TS protein was analyzed with McNemmar and Spearman's tests. The Kaplan-Meier method was used to estimate PFS and OS. Survival rates were compared with the log-rank test. Multivariate analysis of the independent prognostic factor for survival was performed using the Cox proportional hazard regression model with a 95\% confidence interval (CI). A $5 \%$ or lower P-value was considered statistically significant.

\section{Results}

Increased expression of TS mRNA and TS protein in NSCLC

In this study, we first collected 160 clinically annotated NSCLC samples and corresponding normal tissues between January 2006 and March 2010. The baseline patient and disease-related characteristics are shown in Table 1.

TS mRNA was expressed in $73.13 \%$ (117/160) of NSCLC samples and $66.25 \%$ (92/160) of the normal tissue samples (Figure 2), a difference that is statistically significant $\left(\chi^{2}=8.621, P=0.003\right)$. Moreover, levels of TS mRNA were significantly higher in lung squamous cell carcinoma than in lung adenocarcinoma $(0.71 \pm 0.18$ compared with $0.21 \pm 0.23, P<0.05)$.

TS protein was expressed in $66.88 \%(107 / 160)$ of NSCLC tissues, which was significantly higher than that of normal tissues $\left(57.5 \%, 79 / 160 ; \chi^{2}=10.066, P=0.002\right)$. TS protein was mainly expressed in the nuclei, with some in the cytoplasm (Figure 3). In addition, $83 \%$ of lung squamous cell carcinoma showed positive TS staining, which was significantly higher than that of lung adenocarcinoma (61\%; $P=0.01)$.

We then investigated the association between the expression of TS protein and the patients' clinicopathological characteristics. We found that expression of TS protein was significantly associated with tumor histology $(P<0.05)$, but did not associate with other clinical features such as age, gender, disease stage, or ECOG grade $(P>0.05$; Table 1$)$. Expression of TS mRNA was positively

Table 1 Association of TS protein expression with clinicopathological data from patients with NSCLC

\begin{tabular}{|c|c|c|c|c|c|}
\hline Characteristic & $n$ & $\begin{array}{l}\text { Positive expression } \\
\text { of TS protein }\end{array}$ & $\begin{array}{l}\text { Positivity } \\
\text { (\%) }\end{array}$ & $x^{2}$ & $P$ \\
\hline \multicolumn{6}{|l|}{ Age (years) } \\
\hline$<60$ & 72 & 45 & 63 & 1.1 & 0.29 \\
\hline$\geq 60$ & 88 & 62 & 70 & & \\
\hline \multicolumn{6}{|l|}{ Gender } \\
\hline Male & 84 & 51 & 61 & 3.0 & 0.08 \\
\hline Female & 76 & 56 & 74 & & \\
\hline \multicolumn{6}{|l|}{ Disease stage } \\
\hline$\| I I B$ & 108 & 75 & 69 & 1.0 & 0.32 \\
\hline IV & 52 & 32 & 62 & & \\
\hline \multicolumn{6}{|l|}{ ECOG grade } \\
\hline 0 & 48 & 28 & 58 & 2.4 & 0.31 \\
\hline 1 & 74 & 53 & 72 & & \\
\hline 2 & 38 & 26 & 68 & & \\
\hline \multicolumn{6}{|l|}{ Histology } \\
\hline $\begin{array}{l}\text { Squamous cell } \\
\text { carcinoma }\end{array}$ & 41 & 34 & 83 & 6.4 & 0.01 \\
\hline Adenocarcinoma & 119 & 73 & 61 & & \\
\hline
\end{tabular}




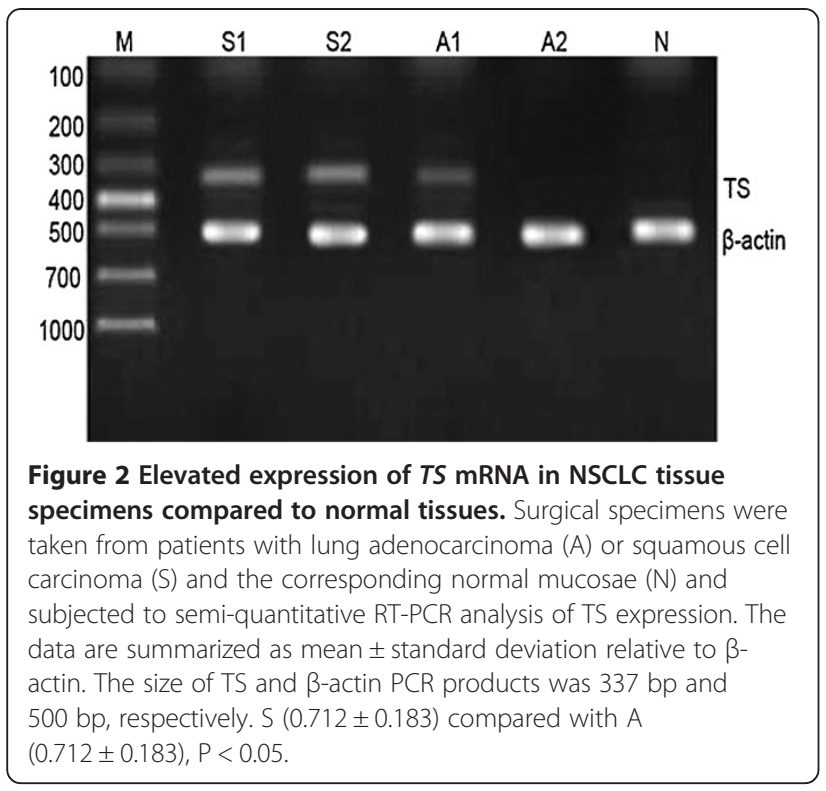

correlated with protein expression as shown by Spearman's test $(\mathrm{r}=0.861, P=0.000)$.

TS gene 3'-UTR 6 bp polymorphism at 1494del associated with clinical outcome of NSCLC patients after pemetrexed treatment

We treated 106 patients with stage IIIB or IV lung adenocarcinoma for up to 6 cycles of pemetrexed (Table 2). The efficacy of pemetrexed treatment was assessed for all 106 patients.

Blood samples were collected from each patient and genotyped for the TS gene 3'-UTR polymorphism at 1494del 6 bp (Figure 1A and C). We found two genotypes of 3'-UTR $1494 \mathrm{bp}$ in these patients, $-6 \mathrm{bp} /-6 \mathrm{bp}$ and $-6 \mathrm{bp} /+6 \mathrm{bp}$. Three samples of each genotype were subjected to DNA sequencing for confirmation of the polymorphisms (Figure $1 \mathrm{~B}$ and $\mathrm{D}$ ). The data showed that $55.7 \%(59 / 106)$ of patients were $(-6 \mathrm{bp} /-6 \mathrm{bp}), 44 \%$ (47/ $106)$ were $(-6 \mathrm{bp} /+6 \mathrm{bp})$, and $0 \%(0 / 106)$ were $(+6 \mathrm{bp} /$ +6 bp). The allelic distribution was in Hardy-Weinberg equilibrium $\left(\chi^{2}=6.6, P=0.83\right)$.

We then determined the association of these polymorphisms and clinicopathological data with sensitivity to pemetrexed, and short- and long-term efficacy of pemetrexed treatment, based on Response Evaluation Criteria in Solid Tumors (RECIST). Statistical analysis showed that gender, tumor stage, and the polymorphism of the TS 3'-UTR 1494del 6 bp were all prognostic factors for short-term efficacy of pemetrexed treatment $(P<0.05$, Table 2$)$. Of the $(-6 \mathrm{bp} /-6 \mathrm{bp})$ patients, $32 \%$ displayed a positive short-term response, whereas the responses of $13 \%$ of the $(-6 \mathrm{bp} /+6 \mathrm{bp})$ patients were also favorable. Furthermore, logistic regression analysis revealed that the difference in short-term efficacy between these 2 genotypes was statistically significant $(P=0.008)$, indicating that the TS 3'-UTR 1494del 6 bp polymorphism is an important prognostic predicator.

The Kaplan-Meier curves (Figure 4) revealed that after treatment with pemetrexed, the median PFSs of $(-6 \mathrm{bp} /-$ $6 \mathrm{bp})$ and $(-6 \mathrm{bp} /+6 \mathrm{bp})$ patients were 3.4 and 2.9 months, respectively. Log-rank analysis revealed that patients with (-6 bp/-6 bp) had significantly better PFS than patients with $(-6 \mathrm{bp} /+6 \mathrm{bp})\left(\mathrm{X}^{2}=12, P=0.0010\right.$, Figure $\left.4 \mathrm{~A}\right)$. Moreover, the median OS of $(-6 \mathrm{bp} /-6 \mathrm{bp})$ and $(-6 \mathrm{bp} /+6 \mathrm{bp})$ patients were 14 and 12 months, respectively. Statistical analysis showed a significantly better OS for patients with

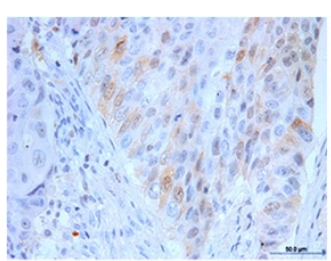

A

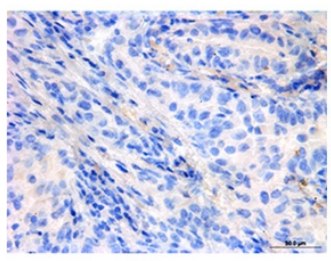

D

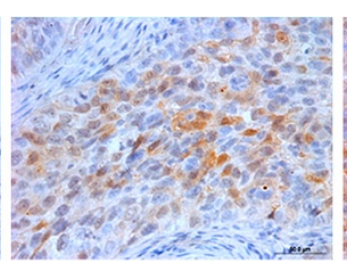

B

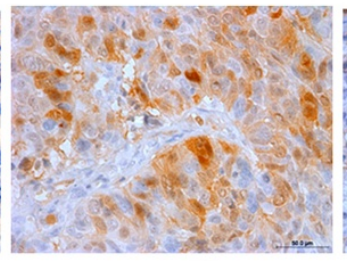

$\mathrm{E}$

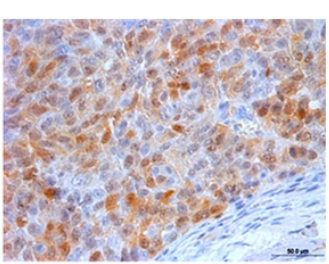

$\mathrm{C}$

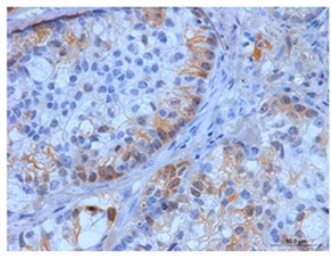

F

Figure 3 Enhanced expression of TS protein in NSCLC compared with the corresponding normal tissues. Paraffin sections from patients with NSCLC were prepared and stained with anti-TS antibody and then reviewed and scored under a microscope. A-C, Representative low, medium, and high levels of TS expression, respectively. D, Negative staining of normal tissues. $\mathbf{E}$, strong expression of TS protein in lung squamous cell carcinoma. $\mathbf{F}$, low level of TS expression in lung adenocarcinoma. 
Table 2 Association of pemetrexed treatment responses with clinicopathological data from lung adenocarcinoma patients

\begin{tabular}{|c|c|c|c|c|}
\hline & \multirow[t]{2}{*}{ No. of patients } & Efficacy & \multirow[t]{2}{*}{$x^{2}$} & \multirow[t]{2}{*}{$P$ value } \\
\hline & & $\overline{\mathrm{CR}+\mathrm{PR}}$ & & \\
\hline \multicolumn{5}{|l|}{ Age (years) } \\
\hline$<60$ & 50 & 16 & \multirow[t]{2}{*}{3.7} & \multirow[t]{2}{*}{0.06} \\
\hline$\geq 60$ & 56 & 9 & & \\
\hline \multicolumn{5}{|l|}{ Gender } \\
\hline Male & 62 & 10 & \multirow[t]{2}{*}{4.6} & \multirow[t]{2}{*}{0.03} \\
\hline Female & 44 & 15 & & \\
\hline \multicolumn{5}{|l|}{ Disease stage } \\
\hline IIIB & 78 & 24 & \multirow[t]{2}{*}{5.6} & \multirow[t]{2}{*}{0.02} \\
\hline IV & 28 & 1 & & \\
\hline \multicolumn{5}{|l|}{ ECOG grade } \\
\hline 0 & 36 & 13 & \multirow[t]{3}{*}{5.0} & \multirow[t]{3}{*}{0.08} \\
\hline 1 & 54 & 10 & & \\
\hline 2 & 16 & 2 & & \\
\hline \multicolumn{5}{|l|}{ Genotype } \\
\hline$-6 \mathrm{bp} /-6 \mathrm{bp}$ & 59 & 19 & \multirow[t]{2}{*}{5.5} & \multirow[t]{2}{*}{0.02} \\
\hline$-6 \mathrm{bp} /+6 \mathrm{bp}$ & 47 & 6 & & \\
\hline \multicolumn{5}{|c|}{ Expression of TS protein } \\
\hline $\mathrm{TS}(+)$ & 67 & 11 & \multirow[t]{2}{*}{5.1} & \multirow[t]{2}{*}{0.02} \\
\hline $\mathrm{TS}(-)$ & 39 & 14 & & \\
\hline
\end{tabular}

the ( $-6 \mathrm{bp} /-6 \mathrm{bp})$ genotype $\left(\chi^{2}=27, P=0.000\right.$, Figure $\left.4 \mathrm{~B}\right)$. Cox regression analysis showed that age, tumor stage, the type of polymorphism, and expression of TS protein of the TS 3'-UTR 1494del 6 bp significantly affected the OS of patients $(P<0.05)$, whereas gender and the ECOG score did not influence the survival significantly (Table 3 ).

\section{Association between adverse drug reactions and TS gene 3'-UTR 1494 bp}

Adverse drug reactions of these patients to pemetrexed treatment were defined in accordance with the National Cancer Institute Common Toxicity Criteria (NCI-CTC) version 3.0 [13]. The most frequently occurring adverse drug reaction was bone-marrow inhibition, followed by gastroenterological discomfort and liver and kidney damage. However, no patients withdrew from treatment due to adverse drug reactions. Patients with the $-6 \mathrm{bp} /-$ $6 \mathrm{bp}$ genotype had more adverse drug reactions to the drug treatment than $-6 \mathrm{bp} /+6 \mathrm{bp}$ patients, but the difference was not statistically significant (Table 4). Overall, the patients tolerated and complied with this drug treatment, making pemetrexed useful for controlling tumor progression and improving the quality of life of these advanced lung cancer patients.

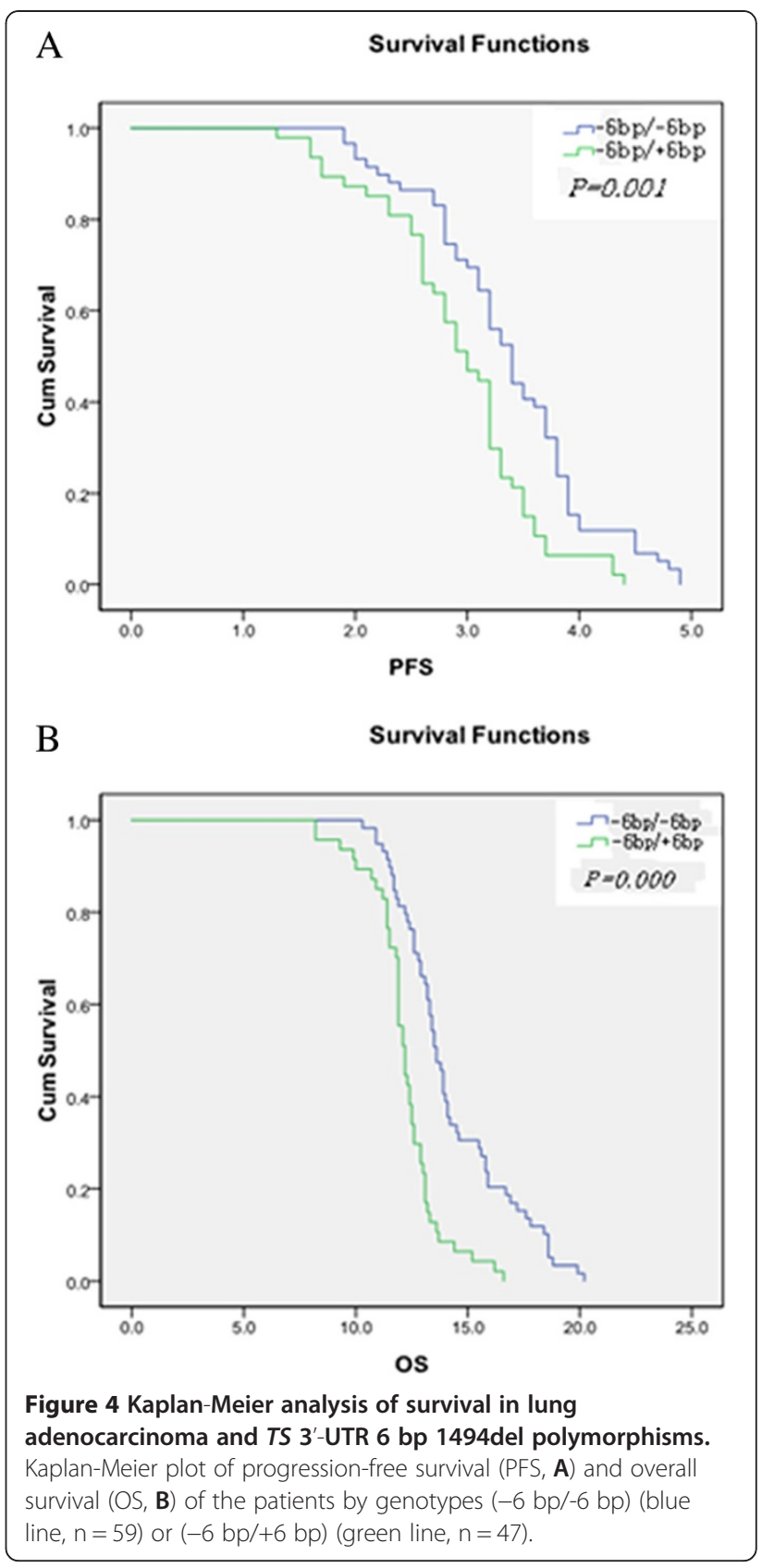

\section{Discussion}

Our current study showed that TS is highly expressed in NSCLC and that polymorphisms of TS 3'-UTR 1494del 6 bp are associated with lung adenocarcinoma patients' sensitivity to pemetrexed treatment. Otake et al. [14] was the first to show TS overexpression in NSCLC, i.e., $60.9 \%$ of 23 resected NSCLC samples displayed TS protein expression. Furthermore, they also performed the fluorodeoxyuridine-5'-monophosphate binding assay and found that TS enzymatic activity ranged from 1.8 to 56.9 $\mathrm{pmol} / \mathrm{g}$ protein in NSCLC samples, indicating that TS may be involved in NSCLC tumorigenesis [14]. Nakagawa 
Table 3 Multivariate analysis of patients' survival according to clinicopathological data and TS gene 3'-UTR 1494 bp polymorphisms

\begin{tabular}{lllllll}
\hline & $\begin{array}{l}\text { Regression } \\
\text { coefficient } \\
\text { (b) }\end{array}$ & $\begin{array}{l}\text { Standard } \\
\text { errors }\end{array}$ & Wald & $\boldsymbol{P}$ & Exp (b) & $\mathbf{9 5 \% ~ C l}$ \\
\hline Gender & -0.31 & 0.22 & 2.0 & 0.16 & 0.73 & $0.48-1.1$ \\
\hline Age & 0.61 & 0.22 & 7.5 & 0.01 & 1.8 & $2.0-2.8$ \\
\hline Tumor stage & 0.77 & 0.24 & 11 & 0.00 & 2.1 & $1.4-3.5$ \\
\hline ECOG grade & -0.27 & 0.16 & 2.8 & 0.10 & 0.80 & $0.55-1.1$ \\
\hline Genotype & 0.92 & 0.27 & 12 & 0.01 & 2.5 & $1.5-4.3$ \\
\hline $\begin{array}{l}\text { Positive } \\
\text { expression of }\end{array}$ & -0.60 & 0.28 & 4.6 & 0.03 & 0.55 & $0.32-1.0$ \\
TS protein & & & & & & \\
\hline
\end{tabular}

et al. [15] also found that NSCLC cell proliferation was associated with increased levels of TS expression, especially in lung adenocarcinoma cells. Our current study showing upregulated expression of TS mRNA and TS in NSCLC tissue specimens compared with normal tissues, confirmed the data of Otake et al. [14] and Nakagawa et al. [15]. The upregulated levels of TS expression in squamous cell lung carcinoma were associated with poor tumor differentiation, which is consistent with a study reported by Ceppi et al. [16].

However, Hashimoto et al. [17] showed that expression of TS mRNA was associated with lymph node metastasis, clinical stage, and tumor cell proliferation of lung adenocarcinoma. Although the data of the present

Table 4 Association between the adverse drug reactions and TS gene 3'-UTR 1494 bp

\begin{tabular}{|c|c|c|c|c|c|}
\hline & \multirow[t]{2}{*}{ Grade } & \multicolumn{2}{|c|}{ Genotype $(\mathbf{n}=$ cases $)$} & \multirow[t]{2}{*}{$x^{2}$} & \multirow[t]{2}{*}{$P$} \\
\hline & & $-/-(\mathbf{n}=59)$ & $-/+(n=47)$ & & \\
\hline \multirow[t]{2}{*}{ Leukopenia } & I, II & 22 & 16 & 0.057 & 0.483 \\
\hline & III, IV & 0 & 1 & 1.241 & 0.449 \\
\hline \multirow[t]{2}{*}{ Neutropenia } & I, II & 21 & 19 & 0.117 & 0.437 \\
\hline & III, IV & 0 & 0 & - & - \\
\hline \multirow[t]{2}{*}{ Thrombocytopenia } & I, II & 10 & 11 & 0.457 & 0.330 \\
\hline & III, IV & 0 & 0 & - & - \\
\hline \multirow[t]{2}{*}{ Nausea, Vomiting } & I, II & 9 & 10 & 0.447 & 0.337 \\
\hline & III, IV & 0 & 1 & 1.241 & 0.449 \\
\hline \multirow[t]{2}{*}{ Diarrhea } & I, II & 11 & 9 & 0.003 & 0.573 \\
\hline & III, IV & 0 & 0 & - & - \\
\hline \multirow[t]{2}{*}{ Constipation } & I, II & 14 & 10 & 0.057 & 0.498 \\
\hline & III, IV & 0 & 0 & - & - \\
\hline \multirow[t]{2}{*}{ Fatigue } & I, II & 15 & 10 & 0.155 & 0.435 \\
\hline & III, IV & 0 & 0 & - & - \\
\hline \multirow[t]{2}{*}{ Renal damage } & $\underline{\text { I, II }}$ & 0 & 0 & - & - \\
\hline & III, IV & 0 & 0 & - & - \\
\hline \multirow[t]{2}{*}{ Liver damage } & I, II & 2 & 1 & 0.143 & 0.590 \\
\hline & III, IV & & & & \\
\hline
\end{tabular}

study showed that TS expression in patients with lymph node metastasis and stage IIIA was higher than that of patients without lymph node metastasis and with stage I or II, the difference did not reach statistical significance.

Polymorphisms of the TS gene have been reported to correlate with clinical outcomes of chemotherapy. For example, Mandola et al. [10] showed that the TS 3'-UTR 1494del 6 bp polymorphism was correlated with low TS expression in colorectal cancer. Dotor et al. [9] reported that colon cancer patients with TS 3'-UTR 1494del 6 bp exhibited better response to 5-FU-based adjuvant therapy. A previous Chinese study [18] reported a similar result, i.e., TS 3'-UTR 1494del 6 bp was correlated with sensitivity to chemotherapy in advanced gastric cancer patients. However, another study reported that there was no association between this polymorphism and clinical outcome after chemotherapy [7]. These data indicate that polymorphisms of TS 3'-UTR 1494del 6 bp may be related to the response to particular chemotherapy agents or with different types of cancer. In our current study, we found an association between TS 3'-UTR 1494del $6 \mathrm{bp}$ polymorphisms and outcome of pemetrexed treatments in lung adenocarcinoma patients.

A previous study reported that the $+6 \mathrm{bp} / 1494$ deletion polymorphism was more frequent in Caucasians (Los Angeles, CA), while the $-6 \mathrm{bp} / 1494$ was dominant in Chinese (Singapore) [10]. Gao et al. [19] found that Chinese patients with gastric cancer had $44.8 \%(-6 \mathrm{bp} /-$ $6 \mathrm{bp}), 44.3 \%(-6 \mathrm{bp} /+6 \mathrm{bp})$, and $7.6 \%(+6 \mathrm{bp} /+6 \mathrm{bp}) T S$ gene polymorphisms. In the present study, the shortterm response to pemetrexed treatment was $32.20 \%$ and $12.77 \%$ in $(-6 \mathrm{bp} /-6 \mathrm{bp})$ and $(-6 \mathrm{bp} /+6 \mathrm{bp})$ patients, respectively, indicating that patients with the $(-6 \mathrm{bp} /-$ $6 \mathrm{bp)}$ polymorphism had a better response rate to pemetrexed treatment than those with the $(-6 \mathrm{bp} /+6 \mathrm{bp})$ polymorphism (HR: 4.382; 95\% CI: 1.462 to 13.130; $P=0.008$ ). A recent clinical trial of stage III NSCLC patients (known as the JMDB trial) with pemetrexed in combination with cisplatin found that the overall response rate was $27.1 \%$ [20]. While the current study supports the effectiveness of pemetrexed for NSCLC patients, the JMDB study did not include an analysis of TS gene 3'-UTR 1494 bp polymorphisms.

The current study found that the PFS and OS between patients with $(-6 \mathrm{bp} /-6 \mathrm{bp})$ and $(-6 \mathrm{bp} /+6 \mathrm{bp})$ were significantly different. The multivariate analysis showed that older age, advanced disease stage, and the TS 3'-UTR $1494 \mathrm{bp}(-6 \mathrm{bp} /+6 \mathrm{bp})$ genotype were prognostic for a poorer outcome. However, these data need to be confirmed in a large perspective clinical trial. In addition, with our current data it was not possible to analyze the association between the TS polymorphisms ( $-6 \mathrm{bp} /-6 \mathrm{bp})$ and $(-6 \mathrm{bp} /+6 \mathrm{bp})$ and induced expression of TS in the NSCLC tissues available to us in this study. This is 
because we were unable to obtain any tissue specimens from pemetrexed-treated patients. Fortunately, a previous study did mechanistically demonstrate the link between them [21].

\section{Conclusions}

This study showed that TS protein is highly expressed in NSCLC and that polymorphisms of TS 3'-UTR 1494del $6 \mathrm{bp}$ are associated with sensitivity of lung adenocarcinoma patients to pemetrexed treatment. Our study suggests that TS gene polymorphisms should be further evaluated as prognostic markers for personalized chemotherapy in lung adenocarcinoma.

\section{Abbreviations \\ 3'-UTR: 3'-untranslated region; CR: Complete response; CT: Computed tomography; dTMP: Thymidine monophosphate; ECOG: Eastern Cooperative Oncology Group; MRI: Magnetic resonance imaging; NSCLC: Non-small cell lung cancer; OS: Overall survival; PBS: Phosphate buffered saline; PD: Progressive disease; PFS: Progression-free survival; PR: Partial response; RECIST: Response Evaluation Criteria in Solid Tumors; SD: Stable disease; TS: Thymidylate synthase.}

\section{Competing interests}

The author(s) declare that they have no competing interests.

\section{Authors' contributions}

XW and YW carried out the molecular genetic studies, participated in the sequence alignment, and drafted the manuscript. YW carried out the immunoassays. JC and YW participated in the sequence alignment. $\mathrm{MH}$ conceived the study and participated in its design and coordination, performed the statistical analyses, and helped draft the manuscript. All authors read and approved the final manuscript.

\section{Acknowledgements}

This study was supported in part by the Department of Education, Liaoning Province (\#L2010286).

\section{Author details}

'Department of Oncology, First Affiliated Hospital of Liaoning Medical College, Jinzhou, China. 'Department of Oncology, Third Affiliated Hospital of Liaoning Medical College, Jinzhou, China.

Received: 9 October 2012 Accepted: 21 January 2013

Published: 25 January 2013

\section{References}

1. Jemal A, Bray F, Center MM, Ferlay J, Ward E, Forman D: Global cancer statistics. CA Cancer J Clin 2011, 61:69-90.

2. Cataldo VD, Gibbons DL, Pérez-Soler R, Quintás-Cardama A: Treatment of non-small-cell lung cancer with erlotinib or gefitinib. N Engl J Med 2011, 364:947-955.

3. Scagliotti GV, Parikh P, von Pawel J, Biesma B, Vansteenkiste J, Manegold C, et al: Phase III study comparing cisplatin plus gemcitabine with cisplatin plus pemetrexed in chemotherapy-naive patients with advanced-stage non-small-cell lung cancer. J Clin Oncol 2008, 26:3543-3551.

4. Chang MH, Ahn JS, Lee J, Kim KH, Park YH, Han J, et al: The efficacy of pemetrexed as a third- or fourth-line therapy and the significance of thymidylate synthase expression in patients with advanced non-small cell lung cancer. Lung Cancer 2010, 69:323-329.

5. Scagliotti GV, Ceppi P, Capelletto E, Novello S: Updated clinical information on multitargeted antifolates in lung cancer. Clin Lung Cancer 2009, 10(Suppl 1):S35-S40.

6. Curtin K, Ulrich CM, Samowitz WS, Bigler J, Caan B, Potter JD, et al: Thymidylate synthase polymorphisms and colon cancer: associations with tumor stage, tumor characteristics and survival. Int I Cancer 2007, 120:2226-2232.
7. Ruzzo A, Graziano F, Kawakami K, Watanabe G, Santini D, Catalano V, et al: Pharmacogenetic profiling and clinical outcome of patients with advanced gastric cancer treated with palliative chemotherapy. J Clin Oncol 2006, 24:1883-1891.

8. Ulrich CM, Bigler J, Velicer CM, Greene EA, Farin FM, Potter JD: Searching expressed sequence tag databases: discovery and confirmation of a common polymorphism in the thymidylate synthase gene. Cancer Epidemiol Biomarkers Prev 2000, 9:1381-1385.

9. Dotor E, Cuatrecases M, Martínez-Iniesta M, Navarro M, Vilardell F, Guinó E, et al: Tumor thymidylate synthase 1494del6 genotype as a prognostic factor in colorectal cancer patients receiving fluorouracil-based adjuvant treatment. J Clin Oncol 2006, 24:1603-1611.

10. Mandola MV, Stoehlmacher J, Zhang W, Groshen S, Yu MC, Iqbal S, et al: A 6 bp polymorphism in the thymidylate synthase gene causes message instability and is associated with decreased intratumoral TS mRNA levels. Pharmacogenetics 2004, 14:319-327.

11. Zhai X, Gao J, Hu Z, Tang J, Qin J, Wang S, et al: Polymorphisms in thymidylate synthase gene and susceptibility to breast cancer in a Chinese population: a case-control analysis. BMC Cancer 2006, 6:138.

12. Therasse P, Arbuck SG, Eisenhauer EA, Wanders J, Kaplan RS, Rubinstein L, et al: New guidelines to evaluate the response to treatment in solid tumors. European organization for research and treatment of cancer, national cancer institute of the united states, national cancer institute of Canada. J Natl Cancer Inst 2000, 92:205-216.

13. Common Terminology Criteria for Adverse Events v3.0 (CTCAE). August 9, 2006.

14. Otake Y, Tanaka F, Yanagihara K, Hitomi S, Okabe H, Fukushima M, et al: Expression of thymidylate synthase in human non-small cell lung cancer. Jpn J Cancer Res 1999, 90:1248-1253.

15. Nakagawa T, Otake Y, Yanagihara K, Miyahara R, Ishikawa S, Fukushima M, et al: Expression of thymidylate synthase is correlated with proliferative activity in non-small cell lung cancer (NSCLC). Lung Cancer 2004, 43:145-149.

16. Ceppi P, Volante M, Saviozzi S, Rapa I, Novello S, Cambieri A, et al: Squamous cell carcinoma of the lung compared with other histotypes shows higher messenger RNA and protein levels for thymidylate synthase. Cancer 2006, 107:1589-1596.

17. Hashimoto H, Ozeki Y, Sato M, Obara K, Matsutani N, Nakagishi Y, et al: Significance of thymidylate synthase gene expression level in patients with adenocarcinoma of the lung. Cancer 2006, 106:1595-1601.

18. Lu JW, Gao CM, Wu JZ, Cao HX, Tajima K, Feng JF: Polymorphism in the 3'untranslated region of thymidylate synthase gene and sensitivity of stomach cancer to fluoropymidine-based chemotherapy. J Hum Genet 2006, 51:155-160.

19. Gao CM, Takezaki T, Wu JZ, Liu YT, Ding JH, Li SP, et al: Polymorphisms in thymidylate synthase and methylenetetrahydrofolate reductase genes and the susceptibility to esophageal and stomach cancer with smoking. Asian Pac J Cancer Prev 2004, 5:133-138.

20. Fleeman N, Bagust A, McLeod C, Greenhalgh J, Boland A, Dundar Y, et al: Pemetrexed for the first-line treatment of locally advanced or metastatic non-small cell lung cancer. Health Technol Assess 2010, 14(Suppl 1):47-53.

21. Hua B, Li M, Shuhang W, et al: Epidermal growth factor receptor mutations in plasma DNA samples predict tumor response in Chinese patients with stages IIIB to IV non-small-cell lung cancer. J Clin Oncol 2009, 27(16):2653-2659.

doi:10.1186/1423-0127-20-5

Cite this article as: Wang et al: Association of thymidylate synthase gene 3'-untranslated region polymorphism with sensitivity of non-small cell lung cancer to pemetrexed treatment: TS gene polymorphism and pemetrexed sensitivity in NSCLC. Journal of Biomedical Science 2013 20:5. 